characteristics, such as a low number of positive lymph nodes and ER-positive disease, have the greatest survival benefit from locoregional recurrence prevention.

The data from many thousands of clinical trial patients reviewed by the EBCTCG investigators continue to provide us with crucially important insights. The data reinforce the important role that radiotherapy has in management of breast cancer, and the fact that the benefits of radiation are complementary to the advances in both surgery and systemic treatment is particularly rewarding. The incremental benefits of each component of treatment contribute to the ongoing success in reduction of breast cancer mortality rates.

\section{Thomas A Buchholz}

The University of Texas MD Anderson Cancer Center, Houston, TX77030, USA

tbuchhol@mdanderson.org

I declare that I have no conflicts of interest.

1 Early Breast Cancer Trialists' Collaborative Group (EBCTCG). Effect of radiotherapy after breast-conserving surgery on 10 -year recurrence and 15-year breast cancer death: meta-analysis of individual patient data for 10801 women in 17 randomised trials. Lancet 2011; published online Oct 20. DOI:10.1016/S0140-6736(11)61629-2.
2 Early Breast Cancer Trialists' Collaborative Group (EBCTCG). Effects of radiotherapy and of differences in the extent of surgery for early breast cancer on local recurrence and 15-year survival: an overview of the randomised trials. Lancet 2005; 366: 2087-106.

3 Early Breast Cancer Trialists' Collaborative Group (EBCTCG). Effects of chemotherapy and hormonal therapy for early breast cancer on recurrence and 15-year survival: an overview of the randomised trials. Lancet 2005; 365: 1687-717.

4 Piccart-Gebhart MJ, Procter M, Leyland-Jones B, et al. Trastuzumab after adjuvant chemotherapy in HER2-positive breast cancer. N EnglJ Med 2005; 353: 1659-72.

5 Romond EH, Perez EA, Bryant J, et al. Trastuzumab plus adjuvant chemotherapy for operable HER2-positive breast cancer. N EnglJ Med 2005 353: 1673-84.

6 Kyndi M, Sorensen FB, Knudsen H, Overgaard M, Nielsen HM, Overgaard J. Estrogen receptor, progesterone receptor, HER-2, and response to postmastectomy radiotherapy in high-risk breast cancer: the Danish Breast Cancer Cooperative Group. J Clin Oncol 2008; 26: 1419-26.

7 Nguyen PL, Taghian AG, Katz MS, et al. Breast cancer subtype approximated by estrogen receptor, progesterone receptor, and HER-2 is associated with local and distant recurrence after breast-conserving therapy. J Clin Oncol 2008; 26: 2373-78.

8 Voduc KD, Cheang MC, Tyldesley S, Gelmon K, Nielsen TO, Kennecke H. Breast cancer subtypes and the risk of local and regional relapse. J Clin Oncol 2010; 28: 1684-91.

9 Woodward WA, Strom EA, Tucker SL, et al. Locoregional recurrence after doxorubicin-based chemotherapy and postmastectomy: implications for breast cancer patients with early-stage disease and predictors for recurrence after postmastectomy radiation. Int J Radiat Oncol Biol Phys 2003; 57: 336-44.

10 Kyndi M, Overgaard M, Nielsen HM, Sorensen FB, Knudsen H, Overgaard J. High local recurrence risk is not associated with large survival reduction after postmastectomy radiotherapy in high-risk breast cancer: a subgroup analysis of DBCG 82 b\&c. Radiother Oncol 2009; 90: 74-79.

\title{
Targeting of household air pollution: interpretation of RESPIRE
}

An estimated 3 million infants and children younger than 5 years die every year from pneumonia in developing countries. ${ }^{1}$ Exposure to household air pollution emitted from biomass fuels has been implicated in about a third of these cases. ${ }^{2}$ Observational and case-control studies have reported an association between exposure to household air pollution and lower respiratory tract infections. ${ }^{3}$ However, until now, no randomised controlled intervention trials had been done in children.

In The Lancet, Kirk R Smith and colleagues of the Randomised Exposure Study of Pollution Indoors and Respiratory Effects (RESPIRE) report a randomised trial that aimed to reduce household air pollution and its subsequent effects on early childhood pneumonia. ${ }^{4}$ The RESPIRE trial, which was undertaken in the Guatemalan highlands from 2002-04, introduced chimney stoves (planchas) in homes using traditional wood fires for cooking. 534 homes with pregnant women or infants younger than 4 months were randomly assigned to either planchas or control (traditional wood fires); the primary outcome was the reduction of physician-diagnosed pneumonia in children with use of standardised criteria. Study participants were followed up until 18 months of age, with weekly visits by fieldworkers, and subsequent referral to local physicians who were masked to intervention status for the assessment and diagnosis of pneumonia.

The scope of the RESPIRE trial is impressive, and the public health implications are potentially monumental. Substantial evidence already exists that the fetus and infants are particularly vulnerable to the effects of exposure to indoor air pollutants because of a combination of their developing lungs, high minute ventilation per unit of bodyweight, and suboptimum metabolism of many toxins. ${ }^{5}$ On the basis of findings from previous studies, carbon monoxide measurements were used as surrogates for exposure to ambient fine particulate matter $\left(\mathrm{PM}_{2.5}\right){ }^{6}$ Increased exposure to particulate matter has been strongly associated with an increased risk of childhood pneumonia. ${ }^{78}$ However, RESPIRE's primary outcome, a reduction in pneumonia, was not met (relative risk 
[RR] 0.84, 95\% Cl 0.63-1.13). Notably, there was a significant reduction in severe pneumonia, the secondary outcome $(0.67,0.45-0.98)$.

How should these mixed results be interpreted? As the investigators acknowledge, the study had some limitations: it might have been underpowered, and fieldworkers were not masked. Additionally, the data suggest that the reduction in household air pollution levels achieved by the planchas was insufficient to provide a more substantial benefit. Although carbon monoxide concentrations were reduced on average by $90 \%$ in the cooking area, mean child personal exposures were reduced only about $50 \%$, from about $2 \cdot 2 \mathrm{ppm}$ to $1.1 \mathrm{ppm}$. This reduction still corresponds to a substantial exposure to $\mathrm{PM}_{2.5}\left(\text { about } 80 \mu \mathrm{g} / \mathrm{m}^{3}\right)^{9}$ that has been associated with respiratory morbidity in children. ${ }^{10}$ Furthermore, the investigators noted broad overlap in exposure concentrations for intervention and control households, suggesting exposure misclassification in the intention-to-treat analyses. When the data were analysed according to child carbon monoxide concentration, there was a significant reduction in the $\mathrm{RR}$ of all physician-diagnosed pneumonia (RR $0.82,95 \% \mathrm{Cl} 0.70-0.98$ ) and severe pneumonia $(0.72,0.59-0.92)$, suggesting substantial clinical benefit associated with increasing reductions in exposure.

Additional analyses could have been informative, such as adjustment for number of cold seasons and consideration of time to initial event that could have provided estimates of the deleterious time window of exposure. Multiple episodes of pneumonia occurred in $11 \%$ of children. A sensitivity analysis that excluded these recurrent infections, arguably not independent events, could have allayed concerns about bias and outlier effects. Because anatomical and epigenetic damages after prenatal exposure to household air pollution could manifest as disease later in life, ${ }^{11,12}$ analysis of whether the intervention instituted during the prenatal period (nearly $50 \%$ of cases) conferred greater protection against early childhood pneumonia than when instituted after birth would be of interest.

In view of these results, are household air pollution interventions now known to reduce pneumonia and, in particular, severe pneumonia in developing countries? Probably so, but only if the intervention achieves a substantial reduction in personal exposure. These results

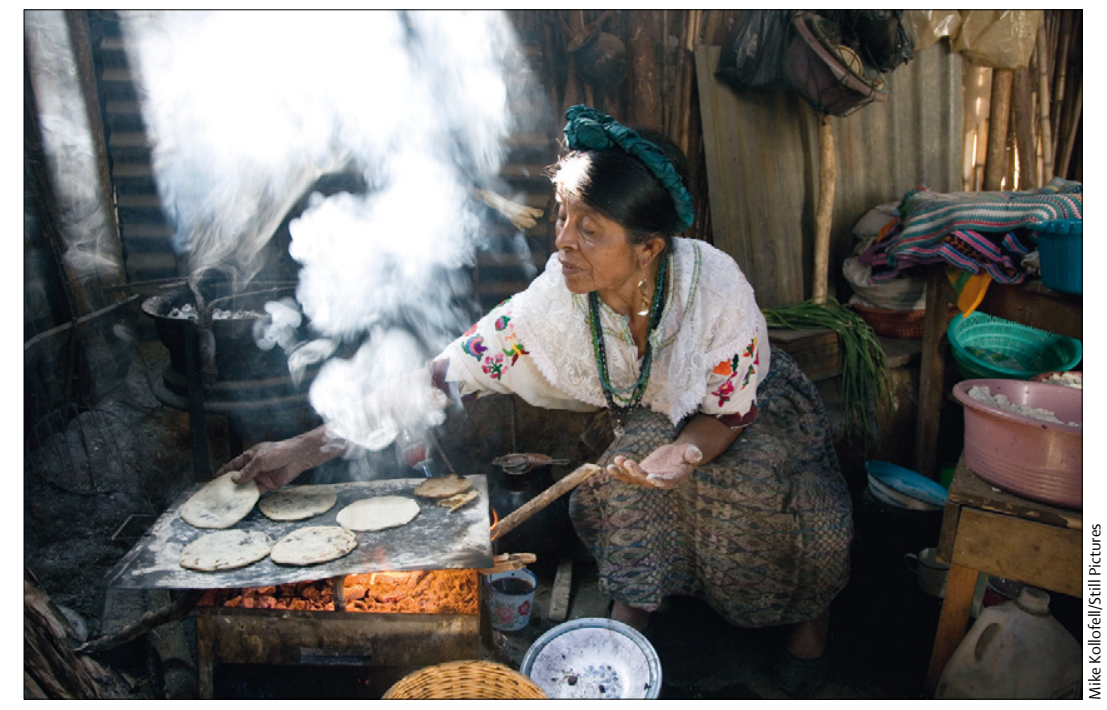

are far from trivial. They should inspire us to improve the interventions further, while continuing to target pregnant women and young children, and test them in other settings. RESPIRE provides important new data that can help to guide much needed remedies for the unacceptably high rates of early childhood mortality in the resource-poor highlands of Guatemala and many other areas worldwide.

\section{${ }^{*}$ Rachel L Miller, Cara L Agerstrand}

Division of Pulmonary, Allergy, and Critical Care Medicine (RLM, (LA), Department of Environmental Health Sciences, Mailman School of Public Health (RLM), and Department of Pediatrics (RLM), Columbia University, New York, NY 10032, USA rlm14@columbia.edu

We declare that we have no conflicts of interest.

1 Rudan I, Tomaskovic L, Boschi-Pinto C, Campbell H, and WHO Child Health Epidemiology Reference Group. Global estimate of the incidence of clinical pneumonia among children under five years of age. Bull World Health Organ 2004; 82: 895-903.

2 Smith KR, Mehta S, Maeusezahl-Feuz M. Indoor air pollution from household use of solid fuels: comparative quantification of health risks. In: Ezzati MLA, Rodgers A, Murray CJL, eds. Global and regional burden of disease attributable to selected major risk factors. Geneva: World Health Organization, 2004: 1435-93.

3 Dherani M, Pope D, Mascarenhas M, Smith KR, Weber M, Bruce N. Indoor air pollution from unprocessed solid fuel use and pneumonia risk in children aged under five years: a systematic review and meta-analysis. Bull World Health Organ 2008; 86: 390-98

4 Smith KR, McCracken JP, Weber MW, et al. Effect of reduction in household air pollution on childhood pneumonia in Guatemala (RESPIRE): a randomised controlled trial. Lancet 2011; 378: 1717-26.

5 Sacks JD, Wichers Stanek L, Luben TJ, et al. Particulate matter-induced health effects: who is susceptible? Environ Health Perspect 2011; 119: 446-54

6 Naeher LP, Smith KR, Leaderer BP, Neufeld L, Mage DT. Carbon monoxide as a tracer for assessing exposures to particulate matter in wood and gas cookstove households of highland Guatemala. Environ SciTechnol 2001; 35: $575-81$.

7 Lacasaña M, Esplugues A, Ballester F. Exposure to ambient air pollution and prenatal and early childhood effects. Eur J Epidemiol 2005; 20: 183-99. 
8 Ezzati M, Kammen DM. Indoor air pollution from biomass combustion and acute respiratory infections in Kenya: an exposure-response study. Lancet 2001; 358: 619-24.

9 Naeher LP, Smith KR, Leaderer BP, Mage D, Grajeda R. Indoor and outdoor PM2.5 and $\mathrm{CO}$ in high- and low-density Guatemalan villages. J Expo Anal Environ Epidemiol 2000; 10: 544-51.

10 Barraza-Villarreal A, Sunyer J, Hernandez-Cadena L, et al. Air pollution, airway inflammation, and lung function in a cohort study of Mexico City schoolchildren. Environ Health Perspect 2008; 116: 832-38.
11 Moshammer H, Hoek G, Luttmann-Gibson $\mathrm{H}$, et al. Parental smoking and lung function in children: an international study. Am J Respir Crit Care Med 2006; 173: 1255-63.

12 Miller RL, Daswani M, Lendor C. Prenatal exposure to air pollution and respiratory outcomes in children. In: Jeorgenson NA, ed. Passive smoking and health research. New York: Nova Science Publishers, 2007: 283-96.

\section{Reporting quality of life in clinical trials: a CONSORT extension}

Results for health-related quality of life (HRQoL) from clinical trials are increasingly used for clinical decision making as well as comparative effectiveness, health policy, and reimbursement decisions. Research suggests that HRQoL information can be used to establish treatment preferences because patients value HRQoL data and can interpret HRQoL findings accurately. ${ }^{1}$ Trials that incorporate $\mathrm{HRQOL}$ as an outcome should therefore be designed, analysed, and reported well.

We did a systematic review of the literature and identified 18 publications with guidelines or standards for reporting of HRQoL in randomised controlled trials, which draw attention to the need for good quality in both trial design and reporting. With regard to trial design, examples of key quality criteria include: the need to use reliable and valid HRQoL measures that are appropriate for the population of interest and that include core outcomes agreed by clinicians, researchers, and patients, ${ }^{2-5}$ timing of HRQoL assessment that is relevant to clinical interpretation of results; minimisation of missing data (since data are often not

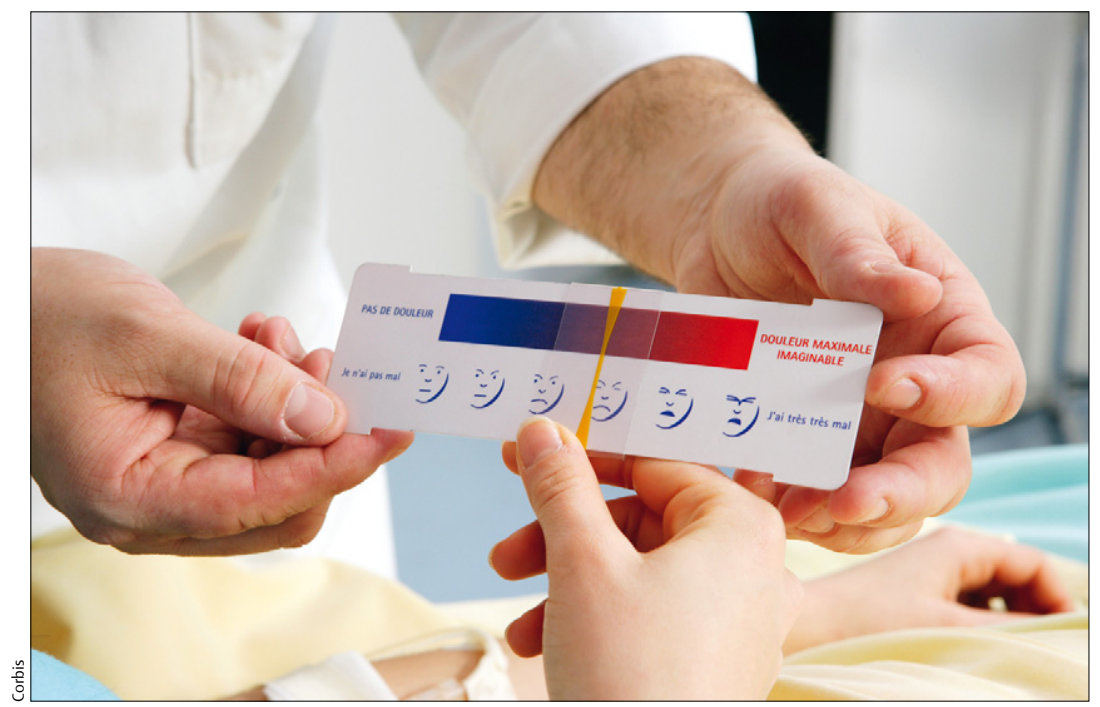

missing randomly, but instead could be linked to other clinical outcomes of interest, with those most unwell not providing data); ${ }^{6}$ and use of prespecified statistical analyses to avoid multiple statistical testing and selective reporting of results.

Given these and other requirements for quality standards in clinical trial design, many authors have recommended standards for $\mathrm{HRQ} O \mathrm{~L}$ reporting so that readers of trial reports can ascertain whether quality standards have been reached. Such standard criteria have included, for example, the provision of a clear rationale for the domains of HRQoL assessment (eg, specific symptoms such as pain, or functions such as activity levels) and the corresponding choice of HRQoL instrument, with cited evidence of the instrument's validity and a statement about the timing of HRQoL assessments used in the trial. Trials should report baseline compliance and the extent of subsequent missing data, since reports that omit details about the amount of missing data, or report substantial missing data, should be interpreted with caution. Type 1 statistical errors, resulting from multiple statistical testing, can be addressed by the requirement that trial protocols prespecify the principal HRQoL postulated outcomes, and their respective timepoints for analysis and reporting in the final trial publication. ${ }^{7}$ Finally, reporting of HRQoL data in a comprehensible, clinically applicable format, and in the context of other trial outcomes might better promote the use of HRQoL data in practice. ${ }^{8}$

Despite these existing recommendations, a systematic review of 794 randomised trials undertaken between 2002 and 2008 that reported HRQoL outcomes across a range of medical conditions showed that only $56 \%$ of trials provided a rationale for the selected outcome measure, 50\% provided an HRQoL hypothesis, 28\% provided information about missing data, and $36 \%$ did not discuss the HRQoL findings in the context of the other trial outcomes. ${ }^{9}$ The review noted that when HRQoL data 